\title{
Analysis of operating conditions of a cooling installation with carbon dioxide
}

\author{
Artur Bieniek ${ }^{1, *}$, Eukasz Mika ${ }^{1}$, and Jan Kuchmacz ${ }^{1}$ \\ ${ }^{1}$ AGH University of Science and Technology, Department of Thermal an Fluid Flow Machines, \\ Krakow, Poland
}

\begin{abstract}
In response to international regulations, natural refrigerants

such as carbon dioxide are more and more frequently used in the refrigeration industry. Due to thermodynamic properties, R-744 is used in the transcritical cycle as an individual refrigerant. In the hereby article, high pressure of $\mathrm{CO}_{2}$ and air temperature values were analysed. The measurements were conducted on the gas cooler side and involved external air temperature values in the summer period between 1 June to 30 September 2018. The "Booster" installation was used in one of Polish supermarkets. Correlations required to determine the optimal pressure of carbon dioxide depending on ambient temperature were presented in the article. The equations presented hereby allowed to maximize the energy efficiency ratio. An optimal high pressure for one of the correlations from literature was calculated on the basis of the measurement of ambient temperature. Actual and optimal pressure values of carbon dioxide were compared in the analysed period of time.
\end{abstract}

\section{Introduction}

Climate changes occurring on the earth trigger the increase of interest in environmental protection, which leads, inter alia, to the reduction of greenhouse gas emissions and the elimination of harmful chemical compounds. The cooling industry is subjected to restrictions in the area of environmental care, mainly due to adverse parameters of synthetic refrigerants used in cooling installations.

The selection of refrigerants was undertaken by the European Commission. As the criterion for withdrawal of individual refrigerants, the ODP indicator was initially adopted, followed by GWP [3]. The Directive of 1 January 2017 prohibits the use of refrigerants with a GWP ratio greater than 150 in new automotive air conditioning installations $[6,11]$. Due to the elimination of subsequent refrigerants, the analysis of the use of natural refrigerants such as carbon dioxide (R-744) has begun.

\footnotetext{
${ }^{*}$ Corresponding author: artbie@agh.edu.pl
} 
As compared to synthetically obtained refrigerants, carbon dioxide is environmentally friendly, even though it is considered one of the main greenhouse gases. The GWP value for $\mathrm{CO}_{2}$ is 1 . In comparison to, for example, the refrigerant R-404A ( $\mathrm{GWP}=3300$ ), 3.3 tons of $\mathrm{CO}_{2}$ affects the greenhouse effect in the same way as 1 kilogram of $\mathrm{R}$ 404A [2].

Pursuant to the PN EN ISO 378 standard, the R-744 is qualified to the group A1, which means that it is non-flammable, non-toxic and safe during operation, unless concentration, threatening one's health or life is exceeded [9]. Despite the very good environmental properties, carbon dioxide, due to its thermodynamic parameters, creates some problems in the design and use of refrigeration systems. Its critical temperature is only $31^{\circ} \mathrm{C}$, at the pressure of 73.75 bar [4]. In this work, the actual high pressure values obtained in the gas cooler were analyzed in a booster system with carbon dioxide installed in one of the Polish supermarkets. The analysis was based on the results of measurements in the summer period, from 1 June to 30 September 2018, because during this period, due to the high temperature of the air, the installation most often worked in supercritical conditions.

\section{Booster systems}

As an independent refrigerant, carbon dioxide can occur in both the subcritical and supercritical cycles. In Polish conditions, due to the high temperature of the upper heat source, the cooling cycle with carbon dioxide is a supercritical cycle. If the temperature of the $\mathrm{CO}_{2}$ on the high pressure side is greater than or equal $31^{\circ} \mathrm{C}$, then the installation works in the supercritical zone, at the pressure exceeding 74 bar, and the gas itself does not condense but it cools. In practice, it happens when the outside air temperature starts to exceed $20-22^{\circ} \mathrm{C}$. In relation to synthetic refrigerants, in the supercritical cycle, carbon dioxide is characterized by a lower energy efficiency, mainly due to the increased work of the compressor. Unfavourable thermodynamic parameters of such a system must be taken into account by system manufacturers, increasing the size of individual system components. With the increase in the size of the carbon dioxide system components, the prices of these systems go up, well above the costs of classic cycle with synthetic refrigerant. Despite thermodynamic and economic difficulties, transcritical cycles are successfully used, among others, in supermarkets, most often in booster systems. An example of a system scheme together with the cycle on the $\log (\mathrm{p})$-h diagram is shown in Figure 1.

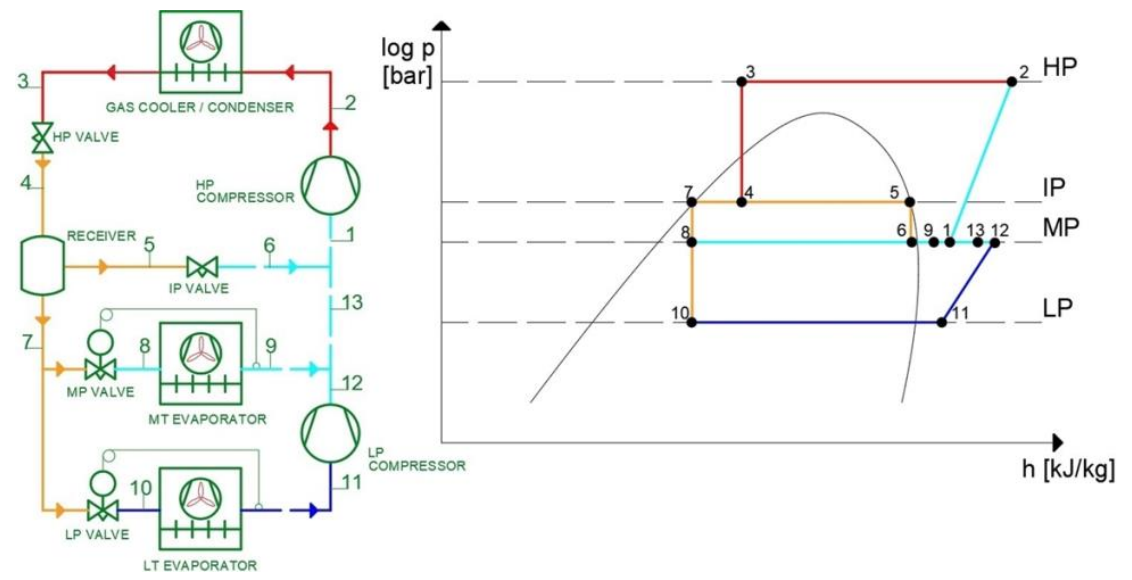

Fig. 1. Scheme of the booster installation with $\log (\mathrm{p})$-h diagram. 
In large supermarkets, gas coolers, through fans, are cooled by air at ambient temperature. Thus, in the summer period, the system often works in a supercritical mode. Therefore, the question arises, what should the pressure of carbon dioxide be in order to maintain the highest possible value of the Energy Efficiency Ratio (EER) or Coefficient of Performance (COP)? Do the actual values of $\mathrm{CO}_{2}$ pressure on the second compression stage obtained under real conditions for supermarket installations coincide with the results of theoretical considerations?

\section{Theoretical, high pressure of carbon dioxide}

The EER or COP of the $\mathrm{CO}_{2}$ system can be affected by factors such as the design of the gas cooler, the pressure in this exchanger and the temperature of carbon dioxide at the outlet of the gas cooler [7]. The exergy analysis shows that regardless of the operating conditions of the gas cooler, it loses about $30.7 \%$ of the total exergy of the system, which is the largest loss in the installation. In comparison, the expansion valve loses about $24.9 \%$, and the compressor $19.5 \%$ of the total exergy [13]. When optimizing such a system, special attention should be paid to the high pressure exchanger, in particular to the high pressure of carbon dioxide, which is dependent on the temperature of the upper heat source. The literature includes many publications that describe the optimal $\mathrm{CO}_{2}$ pressure in the gas cooler, depending on the air temperature or the outlet temperature of the carbon dioxide. Correlations are aimed at achieving the maximum energy efficiency (EER).

Y. T. Ge and S.A Tassou [8], proposed the relationship for supercritical cycle, between high pressure of carbon dioxide and the value of the energy efficiency ratio depending on the air temperature (Figure 2).

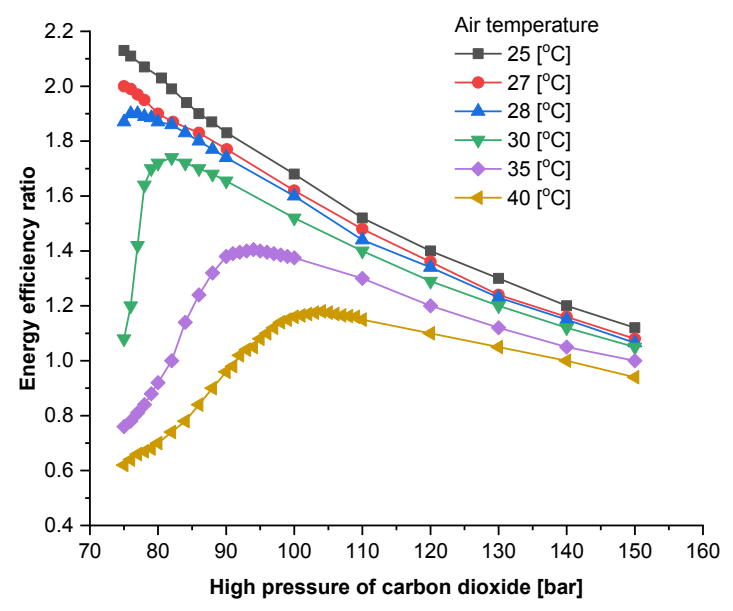

Fig. 2. Variation of energy efficiency ratio with high pressure side and air inlet temperature for transcritical booster installation [8].

In [8], it was observed that the EER decreases with increasing air temperature and for each air temperature value it reaches a different maximum at different values of carbon dioxide pressure. On this basis, an equation describing the optimal pressure (in bars) prevailing in the gas cooler was created depending on the value of the air temperature. The correlation between Ge and Tassou takes the form [8]: 


$$
P_{\text {opt }}=\left\{\begin{aligned}
44.97, & t_{\text {air }}<0^{\circ} \mathrm{C} \\
1.352 \cdot t_{\text {air }}+44.34, & 0^{\circ} \mathrm{C} \leq t_{\text {air }} \leq 20^{\circ} \mathrm{C} \\
75, & 20^{\circ} \mathrm{C}<t_{\text {air }} \leq 27^{\circ} \mathrm{C} \\
2.3426 \cdot t_{\text {air }}+11.541, & t_{\text {air }}>27^{\circ} \mathrm{C}
\end{aligned}\right.
$$

S. Sawalha published a work [12], in which he made the characteristics of the EER for supercritical cycle depending on the high pressure and outlet temperature of carbon dioxide from the high temperature exchanger. The equation describing the optimal pressure of carbon dioxide in the gas cooler was derived. The correlation which is based on theoretical analysis takes the form [12]:

$$
P_{\text {opt }}=2.7 \cdot\left(t_{\text {air }}+t_{\mathrm{CO}_{2}, \text { exit }}\right)-6.1
$$

Y. Chen and J. Gu in their work [5] dealt with the optimization of pressure in the booster system with the internal heat exchanger (IHX) and they proposed a correlation for calculating the optimal pressure of $\mathrm{CO}_{2}[5]$ :

$$
P_{\text {opt }}=2.68 \cdot t_{\text {air }}+0.975=2.68 \cdot t_{\mathrm{CO}_{2}, \text { exit }}-6.797
$$

The publication [10] describes the dependence to determine the optimal pressure of $\mathrm{CO}_{2}$ in a high temperature exchanger. For the supercritical system, the optimal pressure of carbon dioxide depends on two parameters: the outlet temperature of the refrigerant R-744 from the gas cooler and the evaporation temperature. The dependence presented in [10] takes the form:

$$
P_{\text {opt }}=\left(2.778-0.0157 \cdot t_{0}\right) \cdot t_{C O_{2}, \text { exit }}+\left(0.381 \cdot t_{0}-9.34\right)
$$

\section{Measurement and calculation results}

The analysis of the high pressure of carbon dioxide was carried out for the refrigeration installation (booster system) of the Warsaw supermarket. Measurements of high pressure and air temperature were made during the summer, i.e. from 1 June to 30 September 2018. Data concerning air parameters for the Warsaw area came from the register made by the Institute of Meteorology and Water Management in Warsaw. The authors have assumed that an optimal pressure of $\mathrm{CO}_{2}$ could be function of an outside air temperature (according to [8]) without any additional heating, e.g. due to solar radiation. 


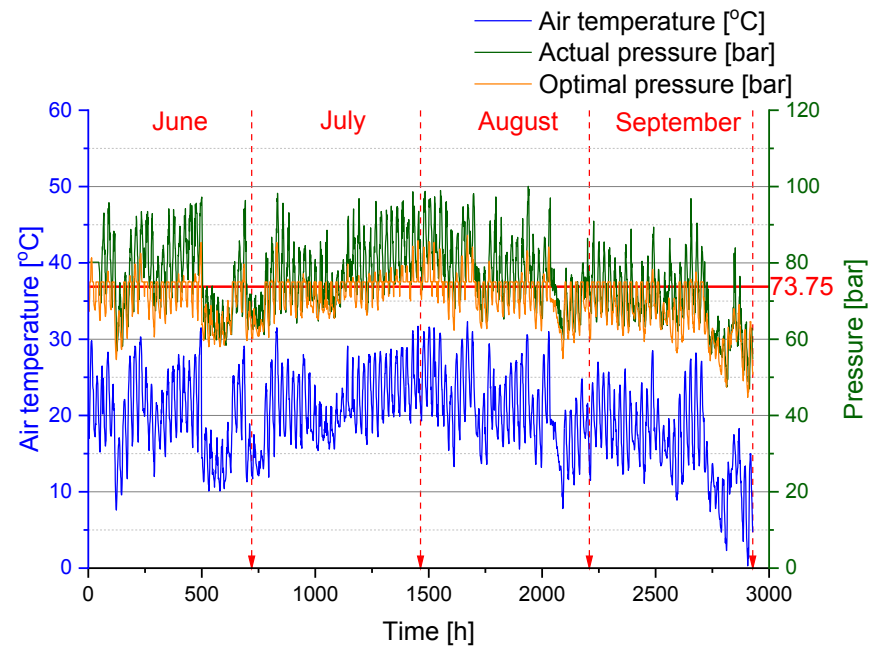

Fig. 3. Theoretical and actual high pressure values in summer period.

A diagram was drawn showing the distribution of the actual and theoretical pressure value as a function of the analyzed time. The total number of hours is shown on the horizontal axis. The analyzed period lasted 2928 hours. On the pressure axis, the pressure limit was set, above which the installation worked in supercritical cycle. The formula (1) was used for theoretical analysis because this correlation takes into account the change in $\mathrm{CO}_{2}$ pressure as a function of the outside temperature and because it can be used for two operating states. The distribution of actual and theoretical pressure is shown in Figure 3.

The actual values of carbon dioxide pressure were significantly higher than the values recommended for maximizing the EER. According to the formula (1), the optimal pressure of carbon dioxide in the high temperature exchanger increases linearly, above the air temperature of $27^{\circ} \mathrm{C}$. As it can be seen from the measurements, the optimal $\mathrm{CO}_{2}$ pressure values are definitely lower than the empirical values. It is worth paying attention to the final phase of the diagram. The optimal and actual $\mathrm{CO}_{2}$ pressure reaches similar values at air temperatures much lower than $20^{\circ} \mathrm{C}$. In this area, the system is in a subcritical state for the majority of the analysed time.

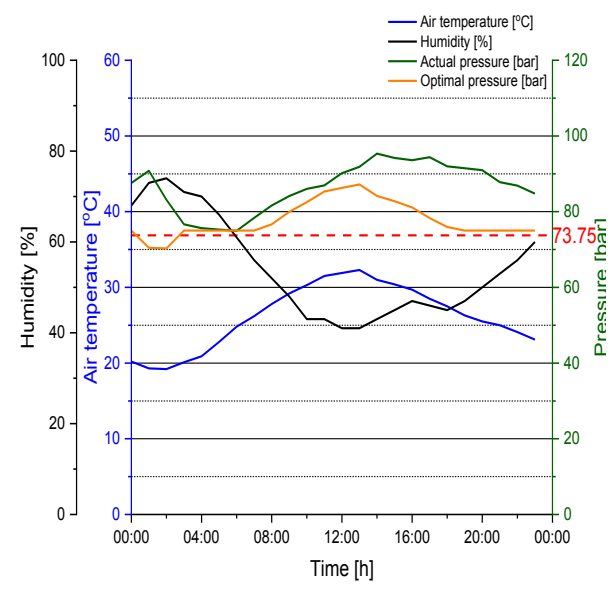

Fig. 4. Pressures values for the warmest day.

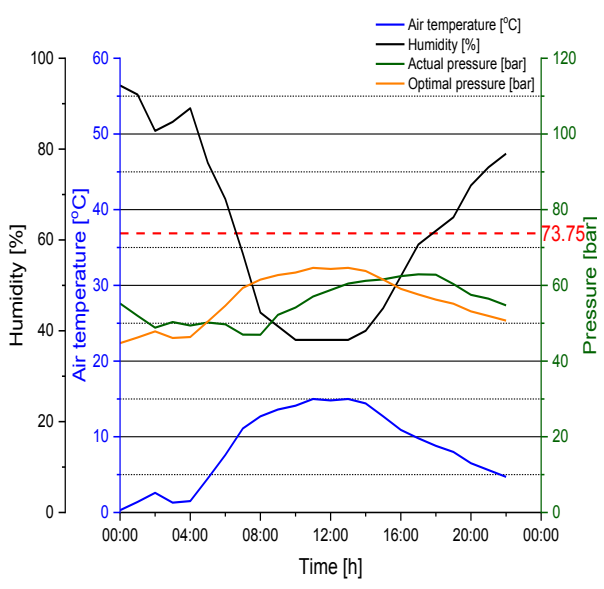

Fig. 5. Pressures values for the coldest day. 


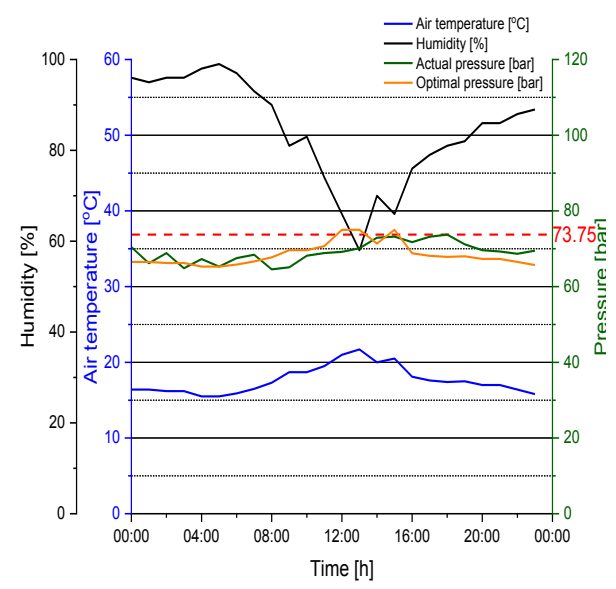

Fig. 6. Pressures values for the highest humidity day..

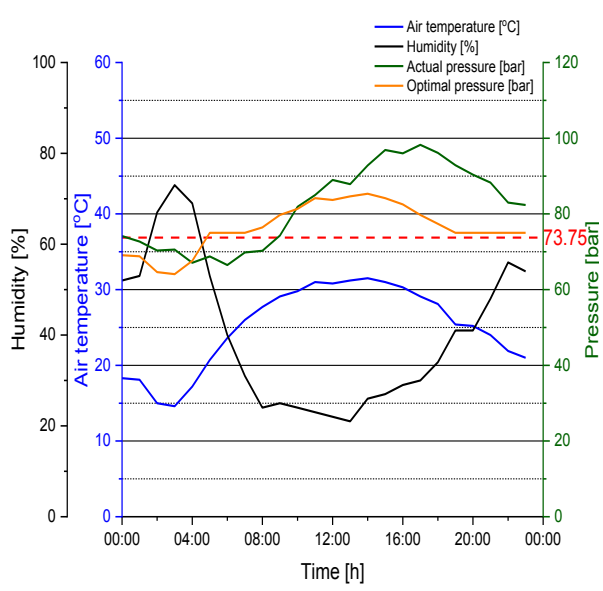

Fig. 7. Pressures values for the lowest humidity day.

The following figures show the daily distribution of carbon dioxide pressure, the pressure resulting from the maximum EER, air temperature and relative humidity. The diagrams were drawn up for the days when:

a) the highest temperature was recorded - Figure 4 (09/08/2018),

b) the lowest temperature was recorded - Figure $5(30 / 09 / 2018)$,

c) the highest relative humidity was recorded - Figure $6(09 / 09 / 2018)$,

d) the lowest relative humidity was recorded - Figure $7(05 / 07 / 2018)$.

Analyzing the diagrams, it was noted that the discrepancy between the measured and optimal value of $\mathrm{CO}_{2}$ pressure depends on the time of a day, and above all on the weather conditions. For high air temperatures, often above $30^{\circ} \mathrm{C}$, there were significant differences between the actual and optimal carbon dioxide pressure values after 12 p.m.. In these areas of the diagrams also much lower relative humidity was recorded as compared to the rest of the day. Figure 4 shows that for the warmest day, the supercritical parameters were maintained around the clock (air temperature range from 20 to $32^{\circ} \mathrm{C}$ ). The measured values of carbon dioxide pressure significantly differed from the correlation described by the equation (1) for most of the day (16 hours). A similar situation is shown in Figure 7. With low relative humidity and high air temperature, the installation worked for the most part of the day in the supercritical cycle and similarly to Figure 4, after 12 p.m., a growing disproportion between the optimal and the actual value of $\mathrm{CO}_{2}$ pressure can be observed.

Figure 6 clearly shows that for the most humid day, with high humidity and low outside temperature, the actual pressure of carbon dioxide was very close to the optimal values. A similar situation took place on the day with the lowest measured temperature (Figure 5). The actual pressure of carbon dioxide oscillated towards the values resulting from the optimization relationship. Disproportion was noticed only about noon with the lowest humidity recorded on that day. In contrast to the other figures, for this day the values of actual $\mathrm{CO}_{2}$ pressure lower than the optimal values were recorded.

Analyzing Figures 4 and 7, one should consider the actual values of outside air temperature available during the operation of the installation. The question is why the system, despite the temperature of the outside air much lower than the critical temperature for $\mathrm{CO}_{2}$, reached such high values of carbon dioxide pressure at 12 o'clock already? The reason of this situation could be the possibility of additional warming up the outside air due to solar radiation. Gas coolers are usually mounted outside supermarkets, usually on the roof. Therefore, it could happen that air can be locally, additionally heated by various elements in the immediate vicinity of the exchanger (or roof cover), which are exposed to 
solar radiation. The amount of moisture in the air and the occurrence of atmospheric precipitation is also worth considering. The water vapour contained in the air can intensify the heat exchange in air heat exchangers.

Figure 8 summarizes the total number of hours for which the difference between the actual and optimal pressure of carbon dioxide was: a) below 1 bar, b) from 1 to 2 bar, c) from 2 to 5 bar, d) from 5 to 10 bar, e) from 10 to 20 bar, f) above 20 bar.

The difference between the optimal and actual pressure of R-744 was less than 1 bar for only 243 hours, which is only $8.3 \%$ of the time period studied. For 278 hours, this difference was in the range of 1-2 bar. If we assumed an acceptable increase or decrease in the high pressure of carbon dioxide at 5 bar and assumed this range as the optimal operating time of the system, the installation would work 1313 hours $(45 \%)$ within the maximum EER. It is worth noticing that for about $20 \%$ of the time, the difference between the actual pressure and the theoretical pressure value was in the range of 10-20 bar, which is a significant deviation.

According to Figure 2, the deviation of the high pressure of $\mathrm{CO}_{2}$ from the nominal point causes a reduction in the EER. Figure 9 presents the characteristics of the decrease in the EER ratio, depending on the difference between the actual and the optimal pressure. The diagram was drawn up on the basis of figure 2 and the work [8].

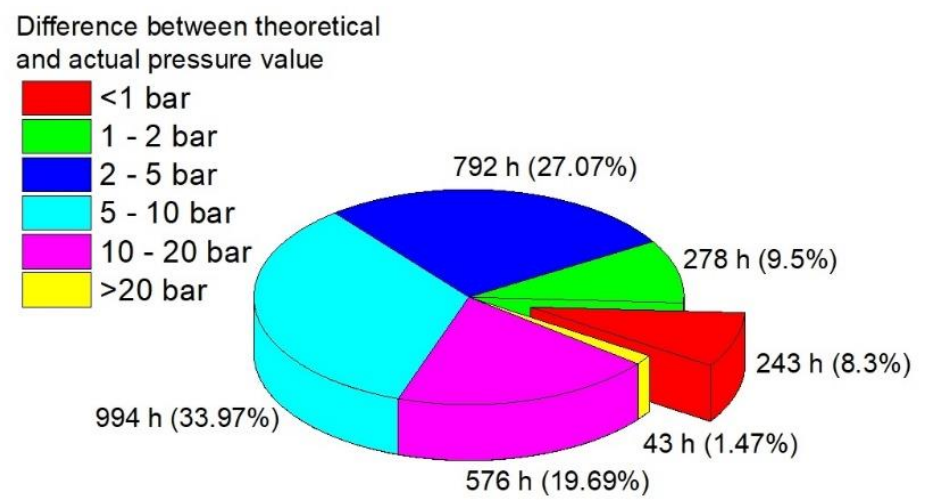

Fig. 8. Amount of hours according on difference between theoretical and actual pressure value.

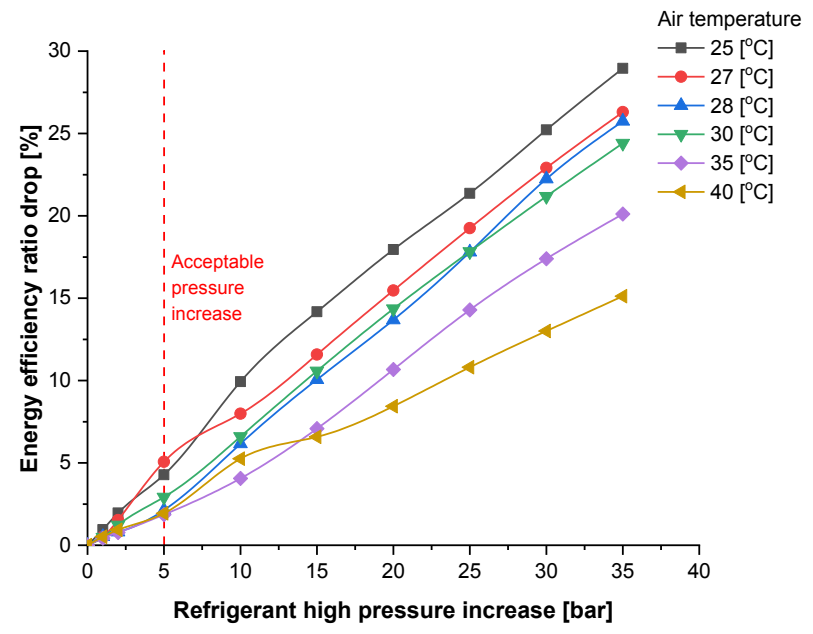

Fig. 9. Energy efficiency ratio drop. 
The increase in $\mathrm{CO}_{2}$ pressure by 1 bar decreased the EER by approximately $1 \%$, in relation to the optimal pressure value. The increase in the high pressure of carbon dioxide by 5 bar (which was assumed to be an acceptable increase in pressure) resulted in the EER drop from 2 to $5 \%$, depending on the air temperature. For the maximum analyzed pressure difference of 20 bar, the EER was 8 to $18 \%$ less than the theoretical value.

\section{Conclusions}

The work shows the impact of the measured high pressure values on an energy indicators of a "Booster" refrigeration installation. Literature sources which present correlations of an optimal pressure value of $\mathrm{CO}_{2}$ on an ambient temperature have been shown. The analysis of the gas cooler functioning in the actual installation was made, on the basis of the meteorological data on particular days. For one of equations proposed, the optimal pressure of carbon dioxide was amounted on the basis of the outside air temperature. The convergence between actual and optimal high pressure values (observed in figures 6 and 7) reveal the assumption made in chapter 4 seem to be proper. In the result of a conducted analysis it has been proved that weather conditions have a significant influence on the high pressure value of carbon dioxide, especially temperature and humidity of the air. Gas coolers are cooled by outside air. It causes the change of parameters of an outside air that may effect parameters of a refrigerant in heat exchangers. Actual and optimal high pressure values of carbon dioxide were convergent on days with the outside air temperature below $20^{\circ} \mathrm{C}$ and the high relative humidity. A reverse situation was recorded for warmer days in the analysed period of time. Actual pressure values of $\mathrm{CO}_{2}$ were much higher than the optimal pressure when the outside air temperature was above $30^{\circ} \mathrm{C}$. A significant difference was noticed for the afternoon when the solar radiation is the highest. Analyzing the diagrams 8 it was noted that the system did not work efficiently for more than half the time (discrepancies between measured and optimal values of the $\mathrm{CO}_{2}$ pressure from 5-20 bar). The EER drop reaches $2-10 \%$ at pressure discrepancies between optimal and measured values from 5-10 bar and 4-18\% at a pressure discrepancy between 10-20 bar. For the largest difference between an optimal and a real pressure $\mathrm{CO}_{2}$ the EER drop can even exceed $20 \%$.

According to the authors' hypothesis, the main cause of the difference between actual and calculated pressures of $\mathrm{CO}_{2}$ is the exposure of the gas cooler on a solar radiation. High-pressure heat exchangers usually are mounted outside or on the roofs of large buildings. The outside air which cools the gas cooler could be heated up by various elements of the installation or by the roof cover. In the results, warmer air gets on the inlet of the gas cooler and its temperature value is a signal for the high pressure controller. In consequence, higher temperature of air on the gas cooler inlet causes reaching higher pressure of $\mathrm{CO}_{2}$. Authors assume that optimal pressure values depend on an outside air temperature which should be measured in the point where disruptors like a solar radiation will be eliminated. This value of the outside air temperature should be taken into consideration within the investigated heat exchanger; however in this case it cannot the point of references. According to the figure 9, the increase of the outside air temperature on the inlet to the gas cooler and indirectly a high pressure value of $\mathrm{CO}_{2}$ causes the drop of an energy efficiency ratio. At a constant temperature of a lower heat source, which is determined by a technological demand, the increase of the temperature of an upper heat source causes the increase of a compression power and higher exploitation costs. Although the detailed analysis was conducted only for one case, this problem occurs in another cooling installations with a carbon dioxide. Therefore authors turn attention to the method of exploitation of gas coolers. One of the propositions on how to solve the problem is to 
choose a shaded place to install a heat exchanger. Moreover, spraying the heat exchanger with water during a high solar radiation is worth considering.

\section{Nomenclature}

COP - Coefficient of performance [-]; EER - Energy efficiency ratio [-]; $\mathrm{P}_{\mathrm{opt}}$ - Optimal pressure $[\mathrm{bar}] ; \mathrm{t}_{0}-$ Evaporation temperature, ${ }^{\circ} \mathrm{C}$; $\mathrm{t}_{\text {air }}-$ air temperature, ${ }^{\circ} \mathrm{C}$; $t_{\mathrm{CO}_{2} \text {, exit }}-$ Outlet $\mathrm{CO}_{2}$ temperature, ${ }^{\circ} \mathrm{C}$

\section{Reference}

1. A. C Beaver, J. M Yin, C. W Bullard, P. S Hrnjak, ACRC Report CR-18 (1999)

2. A Bensafi, CETIAT (2007)

3. T. Bohdal, H. Charun, M. Sikora, Rocz. Och. Środ. 17, 461 (2015)

4. J. Calm, G. Hourahan, Ref. for Susta. (2011)

5. Y. Chen, J. Gu, Int. J. of Reff. 28, 1238 (2005)

6. Directive 2006/40 / EC. Directive 40/2006 of the European Parliament and of the Council of 17 May 2006. Documents 70/156 / EEC

7. D. K. Gupta, S. Kuma, M. S. Dasgupta, J. of Add. Res. in Mech. Eng. 1, 147 (2010)

8. Y. T. Ge, S. A. Tassou, Int. J. of Ref. 34, 540 (2011)

9. ISO 817:2014 Refrigerants - Designation and safety classification

10. S. M Liao, T. S Zhao, A. Jakobsen, Appl. Therm. Eng. 20, 831 (2000)

11. Regulation 517/2014. Regulation (EC) No 517/2014 of the European Parliament and of the Council (EU) of 16 April 2014 on fluorinated greenhouse gases and repealing Regulation (EC) No 842/2006

12. S. Sawalha, Int. J. of Reff. 31, 516 (2008)

13. Y. B. Tao, Y. L. He, W. Q. Tao, Appl. En. 87, 3065 (2010) 